\title{
La Palabra Escrita en la Era de la Comunicación DIGITAL *
}

\author{
Teresa Ayala Pérez ${ }^{* *}$
}

\section{Resumen}

Si bien suele asociarse la comunicación mediática a las imágenes, actualmente gran parte de las comunicaciones se realizan a través de la palabra escrita, la cual no ha perdido su valor y se consolida como el vehículo de la comunicación entre el hombre, los dispositivos y la propia tecnología. En el presente trabajo se intenta reflexionar respecto de la escritura, la comunicación digital y sobre el valor de la escritura en este ambiente, considerada también como una tecnología en sí misma.

Palabras clave: Palabra escrita, comunicación digital, Web, texto, medios de comunicación.

\section{The Written Word in the Age of Digital Signace}

\begin{abstract}
Communication media usually is associated with images, but currently much part of this kind of communications is done through the written word, wich has not only lost its value, but it become the vehicle of communication between humans, devices and own technology. In this paper, we try to reflect about writing, digital communication and the value of writing in this environment like a technology itself in the digital age.
\end{abstract}

Keywords: Written word, digital communication, Web, text, mass media.

Recibido: 05-03-2014

Aceptado: 13-10-2014

* Este trabajo se genera en el Proyecto Fondecyt Regular N 1130294: “Uso de la Web, competencias, motivación y actitud de los estudiantes de pedagogía del área de humanidades respecto de las TIC y la cultura digital".

** Chilena, Magíster en Lingüística y Doctora en Didáctica de la Lengua y la Literatura, Académica Universidad Metropolitana de Ciencias de la Educación, UMCE, Santiago de Chile. teresa.ayala@ umce.cl 


\section{Introducción}

De acuerdo con la Lingüística, el lenguaje es la capacidad humana para comunicarse a través de signos vocales, pero la naturaleza oral del lenguaje no impide que se creen sistemas de escritura que permiten preservar los mensajes, aunque jamás podrán reemplazar al habla. En el siglo XX, debido a las características de los medios masivos de comunicación tales como el teléfono, la radio o la televisión, el código oral y las imágenes parecieron constituirse como la principal forma a través de la cual se transmitía la información. Sin embargo, la revolución tecnológica que representa el uso masivo de Internet a través de la creación de la WWW desde inicios de los años noventa provoca cambios sustanciales en las formas de comunicación, donde la palabra escrita adquiere un nuevo protagonismo en el ambiente informático. Atendiendo a lo anterior, en el presente trabajo se intenta reflexionar respecto del valor simbólico de la escritura, su presencia en los medios de comunicación y su importancia en el ambiente comunicativo generado por la tecnología que caracteriza a la cultura digital.

\section{El hombre tipográfico}

Las antiguas culturas atribuyen a la escritura un origen divino. En diversos textos, como el diálogo "Fedro" de Platón, Sócrates relata el mito de Theuth (el dios egipcio Thoth), creador de la escritura, a quien el rey Thamus advierte los peligros de su invento:

Y ahora tú, precisamente, padre que eres de las letras, por apego a ellas, les atribuyes poderes contrarios a los que tienen. Porque es olvido lo que producirán en las almas de quienes las aprendan, al descuidar la memoria, ya que, fiándose de lo escrito, llegarán al recuerdo desde fuera, a través de caracteres ajenos, no desde dentro, desde ellos mismos y por sí mismos. No es, pues, un fármaco de la memoria lo que has hallado, sino un simple recordatorio. (Platón, 1988: 403)

En la tradición griega, es Hermes quien entrega la escritura a los hombres -y de allí el uso de la palabra hermenéutica- en tanto que en Roma este regalo es atribuido a su contraparte: Mercurio. De acuerdo con Senner (1992: 21) 
En el núcleo de ese vasto abanico de funciones míticas de las deidades -egipcias, sumerias y otras- de la escritura hay un profundo sentido de la importancia existencial de ésta para el poder político y el orden, para la justicia y para la preservación de la vida y el destino humanos. La reverencia de las culturas del Medio Oriente por los valores religiosos y políticos de la lengua escrita representa uno de los factores más inmutables en la historia de la escritura. La Antigüedad reconocía, como lo reconocieron después todas las sociedades cultas, que con la invención de la escritura las ideas y las palabras ya no estaban condenadas al breve destino de la palabra hablada y el recuerdo perecedero de la tradición.

Cuando la escritura, como acción habitual, comienza a ser parte importante en la vida en sociedad y adquiere un papel fundamental en la historia de la civilización, la comunicación entre los individuos se ve modificada, bien sea escritura ideográfica, jeroglífica, silábica o alfabética. Al respecto, McLuhan (1996) afirma que la forma natural de comunicación es la oral, propia de las sociedades tribales, pero con la invención de la escritura se pierde la comunicación inmediata y, por ende, las culturas se destribalizan, como ocurre al alfabetizar pueblos africanos que no poseían escritura alfabética; sin embargo, con el advenimiento de la radio la humanidad vuelve, en cierto sentido, al pasado: "Hemos vuelto a tribalizarnos con la misma inseguridad dolorosa con la que una sociedad no alfabetizada empieza a leer y escribir y a organizar visualmente su vida en un espacio de tres dimensiones" (245). Según el canadiense, el estado tribal se rompe con la incorporación de la palabra escrita y la interiorización de la tecnología del alfabeto fonético traslada al hombre desde el mundo mágico del oído al mundo neutro de lo visual (1985: 28).

La invención del alfabeto, como la invención de la rueda, fue el traslado o reducción de una compleja interacción orgánica de espacios a un espacio único. El alfabeto fonético redujo el uso simultáneo de todos los sentidos que es la expresión hablada, a un mero código visual. Pero el encuentro, en el siglo XX, entre los aspectos alfabético y electrónico de la cultura, confiere a la palabra impresa un papel decisivo en la contención del retorno al África que llevamos dentro. (61) 
En 1969', McLuhan afirmaba que la nueva tecnología es un agente revolucionario, tal cual hoy se manifiesta en los medios eléctricos, pero ya se vio miles de años atrás con la invención del alfabeto fonético, el cual también constituyó una innovación de largo alcance que tuvo profundas consecuencias para el hombre. Agrega que antes de la invención del alfabeto fonético, el hombre vivía en un mundo donde todos los sentidos se equilibraban simultáneamente en un mundo cerrado de profundidad y resonancia tribal, donde una cultura oral es estructurada por el sentido auditivo dominante de la vida. El oído, en comparación con el ojo, frío y neutro, es sensible y contribuye a la perfecta red de parentesco tribal y la interdependencia en la que todos los miembros del grupo existían armónicamente. Otra característica fundamental que distingue al hombre tribal de sus sucesores alfabetizados es que vivía en un mundo del espacio acústico que le otorgó un concepto radicalmente diferente de las relaciones espacio-temporales. Afirma, además, que si bien en el período actual hay más material escrito, impreso y leído que nunca antes, también está la "nueva tecnología eléctrica":

Debido a su efecto de extender el sistema nervioso, la tecnología eléctrica parece favorecer la palabra hablada, inclusiva y que invita a la participación, antes que la palabra escrita y especializada. Los valores occidentales, levantados sobre la palabra escrita, ya han afectado considerablemente a los medios eléctricos del teléfono, de la radio y de la televisión. (McLuhan, 1996: 100)

Afirma que el alfabeto fonético es "una tecnología única" por cuanto "Podría argüirse que el alfabeto fonético, y sólo él, fue la tecnología que se convirtió en el instrumento creador del 'hombre civilizado': individuos iguales ante un código escrito de leyes" (101). La invención de la escritura revolucionó no solo el proceso de comunicación, sino que de toda la civilización, en la medida que la cultura pudo ser preservada para las futuras generaciones, además de tener la ventaja de que los mensajes pudieron llegar más allá del entorno físico inmediato. Pero el camino de registrar el lenguaje oral a través de signos visuales fue largo y complejo desde los jeroglíficos o pictogramas -sistemas simbólicos no alfabéticos conservados en muros, piedras, papiros o pergaminos- hasta los sistemas

1 Entrevista concedida a la revista Playboy. Ver <http://www.mcluhanmedia.com/m_mcl_inter_ pb_01> 
gráficos alfabéticos creados en distintas culturas antiguas de Oriente y que luego se desplazaron a las civilizaciones occidentales.

Griegos y romanos sientan las bases de la cultura occidental gracias a que pudieron conservar sus creaciones y pensamiento a través de textos escritos, mientras que las tres religiones monoteístas se fundan en textos escritos de carácter sagrado: Torá, Biblia (las Sagradas Escrituras) y Corán. Durante la Edad Media, se crean bellos y ornamentados manuscritos elaborados por monjes, sin embargo, estos textos estaban al alcance solo de un grupo reducido de personas, clérigos y nobles, razón por la cual también eran muy pocas las personas alfabetizadas. Por este motivo, la invención de la imprenta con tipos móviles creada por Gutenberg provocó uno de las mayores revoluciones culturales de la historia, a pesar de que de acuerdo con Chartier (2000), los escritos copiados a mano sobrevivieron por mucho tiempo después de la invención de Gutenberg, esto es, siglos XVII e incluso XIX, especialmente en los llamados "libros prohibidos, cuya existencia debía permanecer en secreto, la copia manuscrita continuó siendo la regla" (14). McLuhan, por su parte, sostiene que la imprenta de tipos móviles "fue, en sí, el mayor adelanto en la historia de la escritura fonética, del mismo modo que el alfabeto fonético fue el punto de ruptura entre el hombre tribal y el individualista" (1996: 56).

A partir del siglo XV, entonces, la palabra escrita se constituye en uno de los bienes más preciados del ser humano, no solo porque el saber se democratiza, sino también porque el documento escrito se constituye como el más importante de la vida en sociedad. Por ejemplo, con la llegada de los europeos a América, la oralidad es menoscabada y los textos escritos -como crónicas, cartas de relación o historias- prácticamente crean el imaginario cultural, económico y político hispanoamericano. En este sentido, no está de más recordar a Mignolo (1992), para quien una cultura puede considerar significativos "no solo los textos escritos en la lengua de la cultura, sino también aquellos que, escritos en otra lengua significan, de una manera o de otra (determinable en cada caso), en la cultura en cuestión" (58). Umberto Eco (1995), a propósito de la interpretación de textos, reproduce un fragmento de la obra Mercury: Or the Secret and Swift Messenger (1641) de John Wilkins², donde el autor

2 El naturalista John Wilkins (1614-1672) es considerado el primer criptógrafo inglés. La versión reproducida por Eco es Nicholson, Londres, 1707. El texto mencionado ha sido publicado como Foundations of Semiotics, 1984, Amsterdam/Philadelphia: John Benjamin Publ., tomado de la edición de 1708. 
afirma: "Qué cosa tan extraña debió de parecer este Arte de la Escritura en su primera Invención podemos suponer por los recién descubiertos Americanos, que se sorprendían de ver a los Hombres conversar con los Libros, y a duras penas podían imaginar que un Papel pudiera hablar [...]" (Eco, 1995: 44). El texto narra la historia de un esclavo indio que es enviado por su amo con una cesta de higos y una carta; sin embargo, durante el camino consume gran parte de la fruta y le entrega el resto al destinatario quien, al leer el texto y ver que no coincide el número de higos con los recibidos, acusa al indio, quien niega el hecho "maldiciendo el Papel por ser un Testigo falso y mentiroso". Nuevamente es enviado con la misma carga y consiguiente carta que indicaba el número de higos, los que también come luego de esconder el texto debajo de una piedra, pues si no podía verlo, no podría dar cuenta del hecho. Pero al ser acusado con mayor fuerza, confiesa su falta, "admirando la Divinidad del Papel, y para el futuro promete la mayor Fidelidad de cada Encargo" (Ibíd.). Esta narración probablemente refleje la extrañeza que podría provocar la escritura alfabética en una cultura ágrafa y el valor que se le otorga a este tipo de comunicación, especialmente a partir del siglo XV.

Para Charaudeau y Maingueneau (2005), cuando se habla de lo oral y lo escrito se mezclan diversos ejes desde las perspectiva del discurso: una oposición entreenunciados que pasan por el canal oral, a través de las ondas sonoras, y el canal gráfico (visual) que permite almacenar información y transportarlas a través del tiempo y del espacio; una oposición entre enunciados dependientes del contexto no verbal e independiente de este que coincide con las situaciones dialogal y monologal; una oposición entre dos polos de la producción verbal de una sociedad donde se observan enunciados estabilizados frente a intercambios espontáneos; una oposición antropológica de orden sociocognitivo: la escritura no es solamente una representación de la palabra, pues su aparición abrió de hecho "un nuevo régimen del pensamiento; al proyectarse sobre un espacio bidimensional, se torna capaz, por ejemplo, de constituir cuadros o listas, condición de un nuevo régimen del saber" (224).

\section{La comunicación digital}

La cultura occidental, primero caracterizada por la escritura fonética y, posteriormente, por la presencia de los medios electrónicos de comunicación desde fines del siglo XIX, vive otra revolución tecnológica: la aparición de la informática que utiliza el lenguaje binario y posibilita 
el desarrollo de dispositivos y formas de comunicación que permite transformar la palabra oral o escrita en señales digitales. De acuerdo con algunos especialistas en estudios de la imagen, la actual distinción entre lo analógico y lo digital cobra relevancia a partir del trabajo del diseñador alemán Otl Aicher ${ }^{3}$ (2001), para quien "ya no es posible rehuir la coacción del método digital. La modificación que ha supuesto en nuestra cultura, en nuestro comportamiento, en nuestra comprensión del mundo, es impresionante" (78). Sin embargo, en el paradigma cultural que se inicia en los años 90 con la masificación de Internet a través de la web, el concepto de digital se asocia a una tecnología que codifica la información en bits ${ }^{4}$ mediante dispositivos que permiten su almacenamiento, grabación y transmisión y que, a su vez, requieren de otros dispositivos que permitan su decodificación. No obstante lo anterior, es necesario recordar que esta oposición constituyó uno de los axiomas de la Escuela de Palo Alto en los años '60, cuyos integrantes estudiaron el proceso comunicativo desde diversas perspectivas. Para ellos la distinción se orienta a la comunicación, pero utilizan la incipiente tecnología informática para explicar las dos maneras en que el hombre se comunica:

Estos dos modos básicos de comunicación aparecen también en el campo de los organismos fabricados por el hombre: hay computadoras que utilizan el principio del "todo o nada", de los tubos al vacío o los transistores a las que se llama digitales, porque básicamente son calculadoras que trabajan con dígitos; y hay otra clase de aparatos que manejan magnitudes positivas discretas -análogas a los datos- por lo cual se los llama analógicos. (Watzlawick, Beavin Bavelas y Jackson, 1997: 61)

En rigor, el cuarto axioma exploratorio de la comunicación se plantea en los siguientes términos:

Los seres humanos se comunican tanto digital como analógicamente. El lenguaje digital cuenta con una sintaxis lógica sumamente compleja y poderosa pero carece de una semántica adecuada en el campo de la relación, mientras que el lenguaje

3 Otl Aicher, 1991, Analog und Digital, Berlin: Ernst \& Sohn, aunque el trabajo original corresponde a 1978.

4 Acrónimo de Binary digit, 'dígito binario'. 
analógico posee la semántica pero no una sintaxis adecuada para la definición inequívoca de la naturaleza de las relaciones. (Watzlawick, Beavin Bavelas y Jackson, 1997: 68)

En otras palabras, la comunicación no verbal es analógica, en tanto que la lingüística es digital en la medida que está constituido por unidades claramente distinguibles entre sí, pero para la Escuela de Palo Alto si bien el ser humano es capaz de utilizar ambos modos de comunicación, se comunica de forma digital y prácticamente todos sus logros en la civilización "resultarían impensables sin el desarrollo de un lenguaje digital" (Ibíd, 63). Para Fabbri (2000), en tanto, lo analógico se asocia a lo continuo y lo digital con lo discontinuo; desde esta perspectiva, el lenguaje verbal se sitúa en el lado de lo discontinuo, mientras que la imagen y la música, en el analógico. Sin embargo, en el ámbito informático se trata de una oposición donde en el caso del formato analógico, la traducción de los datos se realiza en forma de impulsos eléctricos, mientras que en el digital, dicha traducción se realiza según el sistema binario de 0 y 1 . De acuerdo con Lunefeld (1999), lo digital es más que solo un término técnico para describir sistemas y medios que dependen de la computación, al igual que lo analógico que lo precedió, pues describe más que un sistema proporcional de representación, al tiempo que lo digital se relaciona con otros términos: electrónica, cibernética, telemática, aunque dichos conceptos son más que una simple nomenclatura tecnológica, pues se están usando como descripciones generales de un período: "I would maintain that 'digital' has a similar function as a placeholder for whatever term we or posterity chooses to describe our inmediate present" $(\mathrm{xvi})^{6}$.

Si bien ya existía el "Protocolo de Internet" (IP) y ya se había enviado el primer e-mail con el uso del signo de la arroba ${ }^{7}$, no existía una tecnología accesible para cualquier usuario para enlazar su computador con muchos otros -tal como lo planteó Theodor Holmes Nelson en 1965 con su idea del hipervínculo- en 1991 el científico británico Tim Berners-Lee envía al newsgroup 6 alt.hypertext un resumen de un proyecto de software que databa de los años 80 y que permitiría que las personas pudieran acceder fácilmentealainformacióna travésdelossistemasinformáticos: ENQUIRE

5 Las cursivas corresponden al texto original.

6 Yo sostendría que "lo digital" funciona como parámetro para cualquier otro término que nosotros o la posteridad elija para describir nuestro presente inmediato (Nuestra traducción).

$7 \quad$ Utilizado como abreviatura del inglés at. 
(Enquire Within Upon Everything 'Preguntar todo sobre todo'). Esa fecha se considera como el inicio del servicio de Internet disponible al público que permite recorrer distintos sitios desde un navegador (Mosaic, 1993; Netscape, 1994; Explorer, 1995) gracias al "Protocolo de Transferencia de Hipertexto" (HTTP, HyperText Transfer Protocol), tecnología que permite crear vínculos (links), entrelazando documentos con otros relacionados con el mismo tema, es decir, la colección de información conocida como la World Wide Web o, simplemente, WWW y Web. Esta tecnología funciona gracias al lenguaje HTML (Hypertext Markup Language, 'Lenguaje de marcas de hiperexto') y al sistema de localización de objetos en la web: la URL (Uniform Resource Locator). En otras palabras, se crea una suerte de 'lenguaje universal' y el HTML puede ser considerado como la base del gran cambio cultural y comunicativo asociado a la tecnología digital, pero que igualmente funciona gracias a la palabra escrita.

A partir de la masificación de Internet se inicia una nueva etapa en la historia de la comunicación humana, puesto que la metáfora de la 'navegación' revela que la web le permite al usuario ir de una página a otra, acción que trae como consecuencia que en la mayoría de los casos no se leen textos completos, sino solo fragmentos escritos. Por otra parte, este hipermedio (Scolari, 2008) reúne a los distintos medios (cine, radio, televisión, prensa) y los usuarios tienen la posibilidad de interactuar con ellos, al tiempo que permite "enlazar de forma interactiva (no lineal) las diversas informaciones que contienen, pero que también se caracteriza porque dicha información puede ser presentada a través de diferentes códigos simbólicos (textos, imágenes fijas y en movimiento, sonidos, etc.)" (Barroso Osuna, 2007). Como afirma Lévy (2007), "este nuevo medio tiene por vocación poner en sinergia y en interfaz todos los dispositivos de creación de información, de grabación, de comunicación y de simulación" (70).

\section{La palabra escrita en la Era de la comunicación digital}

Debido a la importancia de los medios de comunicación, durante las últimas décadas se ha hablado de forma insistente de la cultura de la imagen, especialmente porque el cine, la prensa y la televisión instalan la idea de que "una imagen vale más que mil palabras". En plena década del 60, Guy Debord (1967) afirma que“. El espectáculo no puede entenderse como un abuso de un mundo visual, el producto de las técnicas de difusión masiva de imágenes. Es más bien una Weltanschauung 8 que ha llegado 
a ser efectiva, al traducirse materialmente. Es una visión del mundo que se ha objetivado" (1994: 7). Evidentemente, se trata de una interpretación ideológica respecto de la influencia de las imágenes sobre el individuo, aunque este tema puede ser abordado desde distintos puntos de vista, especialmente porque el hombre, al igual que otras especies, siente fascinación por la hiperestimulación sensorial y el movimiento siempre capta su atención; sin embargo, la televisión multiplica los estímulos visuales y auditivos y a medida que transcurre el siglo XX estos mensajes visuales se caracterizarán por el ritmo cada vez más rápido y por una mayor aceleración de los planos, lo cual trae como consecuencia que en la medida que los televidentes se habitúan a ese ritmo, requieren aún más velocidad de dichos estímulos para obtener gratificación: si no hay cambio resulta aburrido. No obstante lo anterior, es importante recordar que si bien la imagen es parte importante de la naturaleza y de la cultura humana, es el lenguaje el único medio a través del cual es posible la comunicación más completa pues, como afirma Barthes (1971: 13)

Objetos, imágenes, comportamientos pueden, en efecto, significar ampliamente, pero nunca de un modo autónomo: todo sistema semiológico tiene que ver con el lenguaje. La sustancia visiva, por ejemplo, confirma las dos significaciones exigiendo la compañía de un mensaje lingüístico (como ocurre en el caso del cine, la publicidad, los cómics, la fotografía periodística, etc.) de forma que al menos una parte del lenguaje icónico se encuentra en relación estructural de redundancia o de recambio en el sistema de la lengua.

Desdeuna perspectiva semiótica, Eco(2012)afirma que "Incluso sifuese verdad que hoy la comunicación visual supera a la comunicación escrita, el problema no sería oponer la comunicación visual y la comunicación escrita. El problema es cómo mejorar ambas" (52). Sin embargo, como se expuso anteriormente, la web -actualmente sinónimo de Internetmodifica aún más los procesos cognitivos de las personas que acceden a esta tecnología. De esta manera, si bien es cierto que la imagen sigue constituyéndose como parte importante de la comunicación mediática y continúa siendo igualmente significativa en la vida cotidiana de millones de individuos -bien porque se accede directamente a los medios o bien 
a través de computadores, tablets y smartphones-, la información que circula a través de todo estos dispositivos es principalmente a través de la palabra escrita. De cualquier manera, se debe considerar que la mayoría de los mensajes cibernéticos son multimodales (tomando el concepto de Kress y van Leeuwen, 2001), pues está configurada por elementos verbales y no verbales conectados entre sí. Según Martínez Lirola (2008), un texto multimodal o multimedial posee más de un modo de comunicación: verbal, visual, musical. El discurso de este tipo de texto enfatiza el modo visual para atraer la atención de los lectores, pero a la vez combina dichos elementos visuales con los verbales. Para Vandendorpe (2002: 126)

En la nueva cultura del hipermedio, los juegos de encadenamiento entre texto e imagen se multiplican todavía por la consideración de las connotaciones aportadas por el entorno visual [...]. La facilidad con que hoy es posible manipular imágenes, combinarlas con texto y reproducirlas instantáneamente está modificando el viejo orden de la legibilidad y obliga a replantearse la noción de textualidad.

Recorrer la web implica que el usuario debe escribir, en cualquiera de los buscadores, palabras o frases que lo llevarán a los distintos sitios donde deberá leer otros textos escritos; es decir, sin la escritura el ciberespacio simplemente no existe. La palabra escrita es transformada por la tecnología digital en señales que permiten ir de un lugar a otro del espacio electrónico-virtual, por lo cual una persona que no maneja el código escrito, como un niño de corta edad o un miembro de una sociedad ágrafa, no puede hacer un verdadero uso de Internet, aunque sí del dispositivo digital gracias a la interfaz que le permite interactuar, 'comunicarse' con dicho aparato a través de signos icónicos, esto es, que tienen una "similitud topológica entre un significante y su denotado" (Sebeok, 1996: 44). Cada icono tiene un significado que el usuario puede decodificar fácilmente porque representa de forma bastante fiel aquello que representa, por lo que un niño puede encender, apagar o jugar, pero no podrá recorrer la Red.

Para reforzar la idea de que la escritura sigue siendo el elemento comunicativo más importante para el hombre, es posible dar como ejemplo el caso del sitio web YouTube, cuyo lema es "Broadcast yourself", es decir, "trasmítalo usted mismo", slogan donde se ha utilizado el concepto de broadcast que alude tanto a la transmisión de datos, como a 
la radiodifusión o a los medios de comunicación ${ }^{9}$. Este sitio permite ver películas, capítulos de seriales de televisión o videos personales que los usuarios desean compartir, entre otros materiales visuales, pero si bien puede ser considerado como el epítome de la cultura de la imagen, para acceder a esos contenidos es necesario realizar una búsqueda a través de la palabra escrita. La interfaz del sitio contiene un menú con iconos, pero junto a estos aparece la palabra correspondiente. Asimismo, en su página inicial se incluyen imágenes de distintos videos, usualmente los más populares cada día, pero con su respectivo hipervínculo -palabras o frases- y una breve descripción lingüística donde se respetan las reglas ortográficas. Por otra parte, para buscar un video es necesario elegir palabras precisas y el usuario debe decidir, luego de leer, cuál es el enunciado que más se acerca a aquello que desea ver. A modo de ejemplo se muestra la búsqueda de un personaje de animación: mickey mouse, mickey mouse en español, mickey mouse latino, mickey mouse español latino, mickey mouse canciones, etc. La búsqueda arroja distintos resultados, pero siempre en minúsculas, pues ni siquiera los nombres propios poseen esta señal gráfica, por lo cual si bien se trata de "código escrito", no se utilizan reglas ortográficas, sino solo caracteres que forman parte de un código específico. Desde esa perspectiva, estas palabras funcionan únicamente como marcas gráficas de la misma manera es que las que aparecen en la interfaz de un horno microondas o de un cajero automático. Asimismo, gran parte de la información que circula en la web utiliza el inglés, pero como sostiene Roger Chartier (2005: 200)

De una manera más escondida que en el caso de las lenguas inventadas en el siglo XIX, el inglés transformado en "lingua franca" electrónica es una especie de lengua nueva que reduce el léxico, simplifica la gramática, inventa palabras y multiplica abreviaturas (del tipo "I cyou").

Otro caso que prueba el valor y la presencia de la palabra escrita en un mundo digital donde circulan millones de imágenes, es que los usuarios comparten fotografías a través de sitios como Flickr, Instagram, Facebook o Twitter, pero generalmente dichas fotos van acompañadas por títulos, 'etiquetas' o comentarios. Asimismo, a través de las redes

9 Utilizan el concepto en este sentido las cadenas BBC (British Broadcasting Corporation, ‘Corporación Británica de Radiodifusión'), ABC (American Broadcasting Company) o NBC (National Broadcasting Company). 
sociales, millones de mensajes recorren el ciberespacio con una 'etiqueta' o hashtag ${ }^{10}$, es decir, una cadena de caracteres formada por una o varias palabras que van precedidas por el signo \# 'almohadilla, gato, numeral, cardinal' $^{\prime 11}$-uno de los pulsadores del teclado de teléfonos celulares y fijos- el cual se antepone para que el usuario identifique rápidamente los temas, por ejemplo, \#love. El hastag es usual en Twitter que funciona sobre la base del código escrito, pero que permite solo 140 caracteres y al respecto se debe hacer notar que a inicios de $2014^{12}$ el promedio de mensajes (tweets) diarios era de 58 millones y de 9.100 cada segundo, lo cual confirma la presencia de los signos alfabéticos en el ciberespacio. Facebook y Whats App, por su parte, también tienen como código principal el escrito, pues si bien se pueden insertar fotos o videos, principalmente se trata de textos, al igual que los foros, los chat, el desaparecido Messenger y los todavía vigentes correos electrónicos y SMS (Short Message Service).

Los ejemplos mencionados describen aspectos generales en la comunicación digital: a pesar de que las imágenes parecen ser los elementos más importantes, en todos los casos se encuentran relacionadas con textos, es decir, lo que Barthes (1964) llama la función de anclaje, la cual -según este autor- es la más frecuente del mensaje lingüístico y aparece por lo general en la fotografía de prensa y en publicidad; relaciona el texto con la imagen, otorgándole un sentido, complementando lo comunicado por ella. Parafraseando al semiólogo francés, se trata de una descripción denotada, a menudo parcial, de la imagen y la función denominativa corresponde a un anclaje de todos los sentidos denotados posibles del objeto mediante el empleo de una nomenclatura. La postura de Barthes ante el signo lo lleva a considerar al lenguaje -como se mencionó con anterioridad-como el elemento más importante del proceso comunicativo y cualquier otro código depende o se completa en ese sistema sígnico. Desde esa perspectiva, y en pleno auge de los medios tradicionales de comunicación, afirma que:

Actualmente, a nivel de las comunicaciones de masas, parece evidente que el mensaje lingüístico esté presente en todas las imágenes: como título, como leyenda, como artículo de prensa, como diálogo de película, como fumetto. Vemos entonces que

10 Palabra que mezcla hash 'almohadilla, gato o numeral' y tag 'etiqueta'.

11 En inglés, hashtag y cat.

12 Fuente: Twitter, Huffington Post, eMarketer. Ver <http://www.statisticbrain.com/twitterstatistics/> 
no es muy apropiado hablar de una civilización de la imagen: somos todavía, y más que nunca, una civilización de la escritura. (1972: 133)

Lo anterior puede ser aplicado ad pedem litterae a la comunicación digital, pues aunque en los distintos dispositivos o interfaces usados en este ambiente tecnológico, seguimos siendo una civilización de la escritura, y es posible discrepar con McLuhan para quien:

Es cierto que hoy en día hay más material escrito, impreso y leído que nunca antes, pero también está la nueva tecnología eléctrica, que amenaza la antigua tecnología de la escritura, basada en el alfabeto fonético. Debido a su efecto de extender el sistema nervioso, la tecnología eléctrica parece favorecer la palabra hablada, inclusiva y que invita a la participación, antes que la palabra escrita y especializada. Los valores occidentales, levantados sobre la palabra escrita, ya han afectado considerablemente a los medios eléctricos del teléfono, de la radio y de la televisión. (1996: 100)

$\mathrm{Al}$ respecto, es posible comentar que si bien es cierto que radio, cine, televisión y telefonía parecen favorecer el código oral, en la práctica esto no ocurre. Los jóvenes utilizan sus teléfonos celulares, y especialmente los smartphones, para jugar, chatear, enviar mensajes o recorrer la web, pero muy poco para "hablar" y cada vez es más común ver a las personas de todas las edades en lugares públicos comunicarse de manera constante a través del código escrito, digitando mensajes a través de WhatsApp, Twitter, Line o Facebook, mensajes de texto y correos electrónicos. Como se observa, es evidente que el código escrito es el más utilizado en la era digital, especialmente en computadores y teléfonos móviles, pero también se debe considerar que en la cultura occidental el documento escrito es el único que tiene validez en el ámbito académico, jurídico o comercial: se sigue hablando de la "escritura" que se firma al adquirir un bien raíz; se ratifican tratos en notarías donde necesariamente deben quedar registrados por escrito para que tenga valor. En otro ámbito, obras de arte, documentos antiguos o joyas deben estar autentificados a través de certificados escritos para poder transarse comercialmente de manera legal. Para Kress (2010), la escritura se ha utilizado tradicionalmente en reglamentos e instrucciones, pues es lo que se considera oficial; por este motivo, respecto de una ley, el hecho de que alguien no la haya leído no 
cuenta como excusa para transgredirla, puesto que solo basta que haya sido escrita. La clásica cita latina atribuida al escritor romano Patronio ${ }^{13}$ Verba volant scripta manent se utiliza habitualmente hoy en día: 'las palabras vuelan, lo escrito permanece' con el propósito de resaltar la fugacidad y evanescencia del código oral y, por ende, la valoración social que se le da a la palabra escrita. Sin embargo, de acuerdo con Manguel (2005), esta clásica frase antes pudo haber expresado lo contrario: se habría acuñado en alabanza de la palabra dicha en voz alta, que tiene alas y puede volar, en comparación con la palabra silenciosa sobre la página, donde yace inmóvil, muerta.

Sin embargo, en este punto la tecnología digital provoca otro cambio: la reproductibilidad de los mensajes escritos: fotocopias, documentos escaneados son utilizados de forma cotidiana, pero a diferencia de un manuscrito medieval, que resulta único e irrepetible, un documento digital incluso puede ser solo virtual, pues no se lee ni se escribe en un soporte material, sino que dichas acciones solo pueden ejecutarse en aparatos que permiten su codificación y decodificación, lo cual remite al tema de la reproducción técnica de la que hablaba Benjamin (1936) a propósito de la obra de arte:

El ámbito entero de la autenticidad se sustrae a la reproductibilidad técnica (y, por supuesto, no sólo a la técnica). Pero, mientras que lo auténtico mantiene toda su autoridad frente a la reproducción técnica manual, a la que por regla general tacha de falsa, no sucede lo mismo con la reproducción técnica. (2007: 95)

Probablemente por los motivos expuestos, los jóvenes universitarios siguen prefiriendo la lectura de un texto impreso en lugar de la lectura en pantalla, en gran medida porque se le asigna mayor credibilidad, pero también -según se ha constatado en distintos grupos focales- porque sienten que les exige menos esfuerzo desde el punto de vista visual y de comprensión lectora. Humorísticamente, Eco (2012) afirma al respecto que:

Tras haber pasado no más de 12 horas en una consola de ordenador, mis ojos son como dos pelotas de tenis y siento la necesidad de sentarme cómodamente en un sillón y leer un

13 Cayo o Tito Árbitro. 
periódico y quizá un buen poema. Creo que los ordenadores están difundiendo una nueva forma de alfabetización, pero son incapaces de satisfacer todas las necesidades intelectuales que están estimulando. (56)

A pesar de este aspecto negativo, a través de encuestas ${ }^{14}$ se advierte que cerca del $90 \%$ busca información en revistas académicas electrónicas siempre o casi siempre; $73 \%$ aproximadamente afirma leer o descargar libros con fines académicos siempre o casi siempre; cerca del 42,4\% afirma descargar e imprimir los documentos, 15,2\% dice no hacerlo y un 42,4\% solo a veces. Asimismo, si bien para los estudiantes consultados el documento impreso sigue teniendo mayor credibilidad que el digital, admiten que existe un aspecto positivo: la posibilidad de almacenar muchos documentos (libros y artículos) en dispositivos tales como computadoras portátiles, teléfonos, tablets o Kindle y no ocupar espacio o tener que cargar peso en bolsos y mochilas. El 46,9\% dice tener una biblioteca digital, en tanto que cerca del $60 \%$ guarda y lee documentos académicos (sí y a veces) en dichos dispositivos portátiles, información que permite observar en los jóvenes el deseo de apropiarse de textos escritos. Sin embargo, es tal la cantidad de información a la que un usuario promedio tiene acceso, que no necesariamente dicha información será procesada. De hecho, los mismos estudiantes consultados afirman que con la posibilidad de descargar documentos se produce una suerte de "síndrome de Diógenes digital", aludiendo al trastorno de comportamiento que provoca que las personas acumulen objetos de forma compulsiva y sean incapaces de deshacerse de ellos. Al respecto, Chartier (2005) afirma que "Monolingüista o políglota, el mundo de la comunicación electrónica es un mundo de sobreabundacia textual, cuya oferta desborda la capacidad de apropiación de los lectores" (203).

Respecto de la comprensión textual, se han realizado importantes investigaciones respecto de la lectura en pantalla en oposición a la lectura en formato impreso y, una de ellas, realizada en Noruega (Mangen, Walgermo y, Broènnick, 2013), mostró que niños del décimo grado en dos escuelas primarias urbanas tienen un mayor grado de comprensión de un mismo texto si este es impreso, en oposición a los digitales que le

14 Los resultados expuestos corresponden a una tabulación aleatoria de encuestas, por lo cual solo muestran las tendencias que muestra el proyecto. 
leen en pantalla, en formato PDF: "Subjects who read the texts on paper performed significantly better than subjects who read the texts on the computer screen"15 (Mangen et.al., 2013: 65). De acuerdo con los autores del proyecto, si se tiene en cuenta la longitud del texto de estímulo y el hecho de que el texto digital estaba en formato PDF, la diferencia en el rendimiento de la comprensión entre los grupos que leyeron el texto impreso y quienes se enfrentaron al digital podría estar relacionado con problemas de navegación dentro del documento. Al leer en la pantalla, el desplazamiento es inevitable a menos que el texto se encuentra dentro del tamañodela pantalla. Se sabe que el desplazamiento (scrolling) obstaculiza el proceso de la lectura, mediante la imposición de una inestabilidad espacial que puede afectar negativamente a la representación mental del lector y, por ende, la comprensión. Una opinión similar es planteada por Rose (2011), quien efectuó un estudio semejante, pero con estudiantes universitarios, pues plantea que las dificultades que pueden observarse en la comprensión de textos digitales es que el acto de leer en pantalla requiere no solo de los ojos, sino también de las manos para desplazarse por dicho texto, esto es, se trata de una actividad coordinada que requiere dejar de prestarle atención para utilizar el mouse, y la atención se desvía aún más cuando cada pocas líneas se debe buscar para volver a ubicarse: "I must search to relocate myself on the scrolling screen"16 (521).

Por otra parte, si bien el mundo digital mantiene el texto escrito como la base de su funcionamiento, el hecho de que las personas lean y escriban durante todo el día a través de dispositivos electrónicos no implica necesariamente una óptima producción y comprensión textual, especialmente debido a que dichos mensajes suelen breves, no siguen las reglas ortográficas ni de redacción, utilizan acrónimos y elementos abreviaturas no gramaticales, solo por similitud fonética ${ }^{17}$ o signos no fonéticos como los emoticones ${ }^{18}$, por mencionar algunos rasgos de este tipo de comunicación. Junto con lo anterior, resulta importante distinguir entre el uso de la palabra escrita como tal o bien simplemente el uso de caracteres como código específico. Al respecto, Yus (2010) se refiere al

15 Los sujetos que leyeron los textos en papel se desempeñaron significativamente mejor que los sujetos que leyeron los textos en la pantalla del computador (Nuestra traducción).

16 Tengo que buscar para volver a ubicarme y poder desplazarme en la pantalla (Nuestra traducción).

17 Por ejemplo, cy (see you, 'te veo'); mxo 'mucho', $x p$ ? '¿por qué?'.

18 Los emoticones, acrónimo de emotional icons son signos icónicos cuyo propósito es mostrar estados de ánimo. Se descargan o se incluyen en teléfonos, servicios de chat o correo electrónico, como las smilies o 'caritas felices' (?), stickers y uso de letras o signos ortográficos que permiten simular una emoción, como ;) 'guiñar un ojo', U_U 'estar triste', X D 'cara muy sonriente' o X_X 'muerto de cansancio'. 
"texto escrito oralizado"19, puesto que el lenguaje del chat de texto "es un híbrido entre la estabilidad y formalidad de la letra impresa, por un lado, y la cualidad efímera e informal del habla, por otro" (Yus, 2010: 197), que posee características tales como "(Orto)grafía fonética", "(Orto)grafía coloquial", "(Orto)grafía regiolectal", "(Orto)grafía prosódica", "(Orto) grafía interlingüistica", "(Orto)grafía homofónica", sustituciones léxicas, sustituciones grafémicas, abreviaciones, acrónimos, truncamientos y elipsis. De acuerdo con Area y Pessoa (2012:16)

La comunicación en la Web 2.0 está provocando la extensión y consolidación de la "cultura del telegrama" que son potenciados por las características de interacción social de la telefonía móvil, de los blogs y de las redes sociales. Frente a la cultura epistolar del pasado hoy prima la economía de las palabras, y la urgencia en hacerlas llegar pronto al destinatario. [...] La mayoría de los textos de las redes sociales, por el contrario son breves, espontáneos, cortos y poco meditados. Es el triunfo de la inmediatez comunicativa frente a la reflexión intelectual. Es el triunfo de la escritura del SMS, y no del texto narrativo.

Para Kress (1998), en el caso del e-mail se observa una mayor informalidad y una mayor proximidad con el habla que a las características de la escritura formal. Asimismo, sostiene (2003) que los dos modos, escritura e imagen, están regidos por distintas lógicas: la de la escritura todavía está aprendiendo de la lógica del habla y se rige por la lógica de la secuencia de sus elementos en el tiempo, en tanto que la imagen se rige por la lógica del espacio y de la simultaneidad de sus elementos visuales.

Otro aspecto importante de destacar es que no solo en un ambiente digital la palabra escrita sigue dominando el mundo de la comunicación mediática, puesto que actualmente la televisión intenta replicar el ambiente de la Web y en muchos de sus programas la parte inferior de la pantalla va mostrando mensajes escritos que entregan, de forma breve, las principales noticias (cintillo de arrastre o texto crawl), al mismo tiempo que eventualmente se reproducen los mensajes que envían los telespectadores con sus opiniones respecto de lo presentado.

19 El propio autor cita otras denominaciones: texto escrito interactivo (Ferrara et.al. 1991); habla escrita (Elmer-Dewitt, 1994); conversación por escrito (writing conversation, Young, 1994), conversación escrita (written conversation, Blanco Rodríguez, 2002) o conversación tecleada (typewritten conversation, Stein, 2006). 
En otro ámbito, y también bajo el concepto del hipermedio, casi todas las radioemisoras y canales de televisión tienen su propia página web que entrega información a través del código escrito, aunque también ofrecen, como opción, la posibilidad de escuchar la señal en vivo, es decir, a través del código oral. No obstante, y como ya se dijo, a pesar de la constante presencia de la palabra escrita en la comunicación digital, los niveles de comprensión lectora y el uso de estrategias comunicativas en textos escritos son bajos, por lo cual cabe suponer que gran parte de los mensajes que circulan en el ciberespacio son formas pauperizadas de lo que tradicionalmente se entiende por escritura, pues se trataría -en la mayoría de los casos- de mensajes que utilizan el alfabeto, pero que no cumplen necesariamente con los criterios de textualidad o no poseen el grado de reflexión que usualmente se asocia a la elaboración de un mensaje escrito. Lo anterior, sin embargo, se contrapone con excelentes páginas web, académicas o personales, blogs donde se reflexiona en torno a diversos temas, además de sitios donde se reproducen o guardan documentos digitalizados invaluables, revistas académicas o libros que se encuentran al alcance de cualquier usuario que muestran, por cierto, los aspectos positivos de la presencia de la palabra escrita en la Web.

\section{Conclusiones}

A pesar de que la comunicación mediática y digital presentanimágenes de forma abundante, el código escrito sigue siendo el sistema sígnico más importante tanto en la Web como en los medios de comunicación de masas. Actualmente libros, diarios y revistas funcionan tanto en el soporte impreso como en el digital y si en el futuro dejaran de existir los libros impresos, esto no evitaría el uso de la palabra escrita. Al respecto, a pesar de la sobreoferta de textos electrónicos al alcance de cualquier lector que tiene poder adquisitivo y acceso a Internet, las personas -por distintas razones- siguen prefiriendo el texto impreso, lo cual se verifica en que los diarios no han bajado el nivel de lectoría, aparecen nuevas revistas -académicas y magazinescas- de forma regular y el mercado del libro sigue prosperando. De acuerdo con lo anterior, lo importante de destacar es que más allá del soporte, el código escrito es el elemento común, siempre y cuando se trate de lenguaje escrito y no de un código semiótico específico, constituido por caracteres que los usuarios usan de forma convencional en la comunicación digital. 
Por otra parte, la comunicación digital no podría funcionar, y ni siquiera existir, sin la presencia de la palabra escrita, pues el acceso al ciberespacio lo brinda la escritura: el teclado es la llave que abre este espacio electrónico que parece infinito. Los smartphones se distinguen de los teléfonos celulares tradicionales en que prácticamente no se usan para hablar, sino solo para escribir y leer, por lo cual ante esta situación es posible afirmar que la palabra escrita confirma su importancia en la era de la comunicación digital y, aunque llegase un momento en que los mensajes impresos no existan, sin lugar a dudas, el código escrito seguirá permaneciendo como uno de los mayores bienes de la humanidad.

\section{Referencias bibliográficas}

Aicher, O. (2001). Analógico y digital. Barcelona: Ed. Gustavo Gili.

Area, M.; Pessoa, T. (2012). De lo sólido a lo líquido: Las nuevas alfabetizaciones ante los cambios culturales de la Web 2.0. Comunicar, 38 (XIX), 13-20.

Barroso Osuna, J. (2007). La informática, los multimedia y los hipertextos en la enseñanza. Nuevas Tecnologías Aplicadas a la Educación (pp. 151-165). Madrid: McGraw Hll

Barthes, R. (1972). Retórica de la imagen. La Semiología (pp. 127-140). Buenos Aires: Editorial Tiempo Contemporáneo.

Benjamin, W. (2007). La obra de arte en la época de su reproductibilidad técnica. Sobre la fotografía (pp. 91-109). Valencia: PRE-TEXTOS.

Charaudeau, P.; Maingueneau, D. (2005). Diccionario de análisis del discurso. Buenos Aires: Amorrortu.

Chartier, R. (2000). Las revoluciones de la cultura escrita. Barcelona: Gedisa. . (2005). El presente del pasado. Escritura de la historia, historia de lo escrito. México: Universidad Iberoamericana.

Debord, G. (1994). La sociedad del espectáculo. Santiago: Nexo.

Eco, U. (1995). Interpretación y sobreinterpretación. Cambridge University Press.

(2012). De Internet a Gutenberg. La comunicación: De los orígenes a Internet (pp.49-64). Barcelona: Gedisa. 
Fabbri, Paolo (2000). El giro semiótico: las concepciones del signo a lo largo de la historia. Barcelona: Gedisa.

Genette, G. (1989). Palimpsestos. Madrid: Taurus.

Kress, G. (1998). Visual and Verbal Modes of Representation in Electronically Mediated Communication: The Potentials of New Forms of Text. En Ilana Snyder, Michael Joyce (Ed) Page to Screen: Taking Literacy Into the Electronic Era (pp. 53-79). New York: Routledge.

. (2003). Literacy in the New Media Age. London: Routledge.

Kress, G. y Leeuwen van. T. (2001). Multimodal Discourse: The Modes and Media of Contemporary Communication Discourse. Londres: Arnold.

Lévy, P. (2007). Cibercultura. La cultura de la sociedad digital. México: Ed. Anthropos.

Lunenfeld, P. (1999). Screen Grabs: The Digital Dialectic and New Media Theory. Cambridge, Massachussets: The MIT Press.

Mangen, A., Walgermo B. R., Broènnick, K. (2013). Reading linear texts on paper versus computer screen: Effects on reading comprehension. International Journal of Educational Research, (58), 61-68.

Manguel, A. (2005). Una historia de la lectura. Barcelona: Random House Mondadori.

Martínez Lirola, M. (2008). Las relaciones entre las características lingüísticas y visuales de las noticias sobre inmigración en la prensa gratuita y su relación con la audiencia. Discurso y Sociedad, 2 (4), 799-815.

McLuhan, M. (1985). La Galaxia Gutenberg. Génesis del "Homo Typographicus". Barcelona: Planeta-De Agostini S.A. . (1996). Comprender los medios de comunicación. Barcelona: Paidós.

Mignolo, W. (1992). Cartas, crónicas y relaciones del descubrimiento y la conquista. Historia de la literatura hispanoamericana, Tomo I, Época Colonial. Madrid: Cátedra. 
Miquel, R. (2011). Las teorías de la Comunicación ante el reto de las Tecnologías de la Información y la Comunicación (TIC). PortalComunicación InCom-UAB. Institut de la Comunicació, Universidad Autónoma de Barcelona [en línea]. Disponible en http://www. portalcomunicacion.com/uploads/pdf/59_esp.pdf

Platón. (1988). Fedro. Diálogos. Tomo III (pp. 289-413). Madrid: Gredos.

Rose, E. (2011). The phenomenology of on-screen reading: University students' lived experience of digitised text. British Journal of Education Technology, 42, (3), pp. 515-526.

Scolari, C. (2008). Hipermediaciones. Barcelona: Gedisa.

Sebeok, T. (1996). Signos: una introducción a la Semiótica. Buenos Aires: Paidós.

Senner, W. (Comp.). (2001). Los orígenes de la escritura. México: Siglo XXI Editores.

Vandendorpe, C. (2002). Del papiro al hipertexto. Buenos Aires: Fondo de Cultura Económica.

Watzlawick, P.; Beavin Bavelas, J.; Jackson, D. (1997). Teoría de la Comunicación Humana. Barcelona: Herder.

Yus, F. (2010). Ciberpragmática 2.0. Barcelona: Ariel. 